Check for updates

Cite this: RSC Adv., 2017, 7, 26335

Received 23rd January 2017

Accepted 9th May 2017

DOI: 10.1039/c7ra01016h

rsc.li/rsc-advances

\section{Life cycle assessment in wastewater treatment: influence of site-oriented normalization factors, life cycle impact assessment methods, and weighting methods $\uparrow$}

\begin{abstract}
Shunwen Bai, ${ }^{a}$ Xiuheng Wang, ${ }^{a}$ Xuedong Zhang, ${ }^{\mathrm{b}}$ Xinyue Zhao ${ }^{\mathrm{a}}$ and Nanqi Ren (DD *a
This present study aims to analyze the differences in results of different site-directional life cycle assessment (LCA) methods applied in the field of wastewater treatment. Site-generic methods were employed and compared with China-specific methods on a full-scale wastewater treatment case. A set of Chinese normalized factors were developed and employed to compare with world normalization factors. No substantial discrepancies in results were obtained from the two different sets of normalization factors. In the phase of life cycle impact assessment, the e-Balance showed substantial discrepancies in results, compared with the CML method that is widely applied in LCA. The discrepancies were mainly attributed to the cause that in e-Balance more emphasis is on regional water pollution potential (that is: chemical oxygen demand (COD) as an independent impact category). Moreover, discrepancies in the results were also investigated by applying different site-directional weighting methods. Besides the specific locations where the weighting methods were designed for, this study showed that employing different environmental indicators in impact categories was another important factor that resulted in differences in the LCA results of the different weighting methods.
\end{abstract}

\section{Introduction}

Numerous environmental issues are caused by complex global supply systems, production techniques, and complicated consumption patterns associated with the modern economy. Using life cycle assessment (LCA) it is possible to assess all impacts within the complete value chain (from "cradle to grave"), which is conducive to identifying the most environmentfriendly improvement strategies and avoiding burden shifts., ${ }^{\mathbf{1} 2}$ According to ISO standards, the general structure of LCA methodology includes four steps..$^{3-5}$ The first step is the definition of goal and scope, which includes clarifying the aim of study and specifying the system boundaries. The second step is analyzing life cycle inventory, collecting data, and compiling a list of input and output flows in each process. Life cycle impact assessment (LCIA) is the third step. Characterization methods have been developed in this step to calculate the impacts within different environmental impact categories, and normalization factors and weighting factors are applied to obtain a single value

${ }^{a}$ State Key Laboratory of Urban Water Resource and Environment, School of Environment, Harbin Institute of Technology, Harbin 150090, China. E-mail: rnq@ hit.edu.cn; baishunwen@163.com; Fax: +86-04516282099; Tel: +86-04516282099

${ }^{b}$ Section Sanitary Engineering, Department of Water Management, Delft University of Technology, Stevinweg 1, 2628CN, Delft, The Netherlands

$\dagger$ Electronic supplementary information (ESI) available. See DOI: 10.1039/c7ra01016h for the evaluated scenario. Interpretation is the final step to present and discuss results of the impact assessment.

In wastewater treatment, this method can be used to evaluate the impacts of the changes that are happening or will happen. ${ }^{6-16}$ For example, the related LCA studies include the improvement of the operation of municipal wastewater plant (WWTP), ${ }^{17}$ the comparison of alternative wastewater sludge treatment systems, and the development of technologies for wastewater recycling. ${ }^{18}$ Nowadays, due to the stringent regulations for pollutants removal in WWTPs, LCA results are conductive to and needed to compare the environmental effects of different control strategies that aim to reduce emissions of pollutants. ${ }^{19}$

Intensive LCA studies have been carried out in wastewater treatment. However, most of the studies applied only one type of LCA methods to carry out the trade-off analysis to obtain suggestions and further provide guidance from the LCA results. Different methods have been developed in various LCA steps, ${ }^{\mathbf{2 0 - 2 5}}$ but few LCA studies in wastewater treatment explained why a specific method was chosen. Furthermore, little attention was given to the influence of the chosen LCA methods on the results and the comparisons among the methods. In the study of Ortiz et al. (2007), three methods (CML 2000, EcoPoints 97, Eco-Indicator 99) were employed, but no comparative discussions concerning influence of methods were addressed. Only Renou et al. (2008) studied the influence of 
method selection in a case study of a full-scale WWTP. The authors concluded that no substantial discrepancies in results were observed within impact categories representing global environmental impact, while a great variation was generated by various LCIA methodologies associated with the categories of toxic impact. It should be noted that for wastewater treatment the scenarios have direct impacts on the regional environments. Different site-directional LCA methods (the methods engaging different regions) may have different influences on the final LCA results. However, the study of Renou et al. (2008) did not take it into account. Some site-specific eutrophication characterization methods have been developed to characterize the regional effect of nutrients into LCA calculation framework, ${ }^{26-30}$ including the site-specific factors for eutrophication potential, the fate model for phosphorus emissions on different scales, and the spatially differentiated factors with respect to different emission sources. However, no comparative studies were performed for these sitespecific methods (the methods engaging specific regions) to examine how and to what extent these methods would generate results and the results vary with the site-generic methods (the methods engaging no specific regions). Additionally, these sitespecific methods all focused on the eutrophication potential, but eutrophication was not the single reason why contaminated aquatic environment was formed.

The aim of this study was to systematically compare the results from the site-generic LCA methods and the Chinaspecific LCA methods (the methods engaging specific China context) in terms of normalization factors, LCIA methods, and weighting methods on a full-scale Chinese wastewater treatment case. Firstly, a set of normalization factors were developed for China context, and a comparative study was performed to explore whether different site-directional normalization factors would produce discrepancies in results. Secondly, a site-generic LCIA method (CML) and a China-specific LCIA method (eBalance) were selected to carry out the comparison to examine the differences in outputs generated from the methods. Thirdly, different site-directional weighting methods were compared using BEES, EPS and EDIP as the site-generic weighting approaches and ECER-115, ECER-125 and ISCP-2009 as the China-specific weighting approaches.

\section{Methodology}

\subsection{Case study and scenarios description}

One wastewater treatment plant (WWTP), being operated in Heilongjiang Province in China, was considered in this study as the base case. The WWTP employs a cyclic activated sludge system and has a daily capacity of $10000 \mathrm{~m}^{3}$ sewage. Four discharge scenarios were assumed on the WWTP effluent. Starting from the most stringent, they are tertiary treatment (scenario-1), intermediate treatment (scenario-2), basic treatment (scenario-3), and no treatment (scenario-4). The scenario3 represents the secondary treatment in WWTP, requiring biological processes to meet basic function of removal of pollutants but without phosphorus removal and tertiary treatment. The scenario-2 strategy represents the high load secondary treatment plus the removal of phosphorus. Based on scenario-2, the scenario-1 also integrates a tertiary treatment stage, including coagulation, sedimentation, and filtration. More detailed information about the WWTP facilities and the control strategies were described in the previous study carried out by Wang et al. $^{19}$

\subsection{Function unit and system boundary}

In this study, $10000 \mathrm{~m}^{3}$ sewage per day was employed as functional unit, and the operational phases of the WWTP were considered as system boundaries. For the input of each scenario, the electricity production, chemicals consumption and transportation, and other substance additions were considered. Besides, the outputs of all emissions of water pollutants, harmful gases, and waste sludge were taken into account for the LCA. Detailed data about the input and output are shown in Table $\mathrm{S} 1 . \dagger$

\subsection{Life cycle impact assessment}

Two methods were chosen in the LCIA. One is CML, which was developed by Leiden University and used as site-generic LCA method in this study. ${ }^{20}$ Impact categories involved in this methodology included: eutrophication (E), acidification (A), freshwater aquatic ecotoxicity (FAET), human toxicity (HT), ozone depletion (OD), photochemical oxidation (PO), global warming (GW), abiotic depletion of fossil fuels (ADF), and abiotic depletion of elements (ADE). The second method is eBalance, which was designed specifically for China context and developed by IKE Company (http://www.ike-global.com/), a Chinese company focusing on the development and utilization of LCA. The e-Balance method included the following impact categories, i.e., eutrophication, global warming, acidification and abiotic depletion of fossil fuels. In addition, a new impact category named chemical oxygen demand (COD) was defined in e-Balance to represent the potential impact of water pollutants in terms of depletion of dissolved oxygen in receiving water, with characterization factor and normalization factor included. The new catalog and the factors were integrated into the software that was developed by the IKE and used for eBalance evaluation. Normalization methods were used to convert characterization results of all impact categories into dimensionless scores. One set of normalization factors is the World normalization factors ( $\left.\mathrm{NF}_{\text {World }}\right)$, covering an extensive range of environmental interventions collected for global systems. ${ }^{31}$ Another set of normalization factors is the Chinese normalization factors $\left(\mathrm{Ch}_{\mathrm{NF}}\right)$, which were developed in this study following the calculation of $\mathrm{NF}_{\text {World }}$. Six weighting methods were applied in this study. For the site-specific methods, BEES, EPA, and EDIP were chosen. BEES (Building for Environmental and Economic Sustainability), a panel-based weighting method, was developed for the United States building sector. ${ }^{32}$ EPA was often used as site-generic weighting method in LCA studies and was also employed in this study. The EDIP method was developed in a Danish project on a basis of Danish policy targets, and provides ready-to-use factors for LCA practitioners. For the China-specific methods, ECER-115, ECER-125, and ISCP-2009 were chosen. Weighting factors of ECER-125 and 
ISCP-2009 were chosen from e-Balance computer software. ECER-115 and ECER-125 were developed in the National 11th Five-Year Plan and the National 12th Five-Year Plan, respectively. ISCP-2009 was developed in the 2nd conference of Chinese Life Cycle Management.

\section{Results}

Chinese normalization factors $\left(\mathrm{Ch}_{\mathrm{NE}}\right.$ in Table $\left.\mathrm{S} 2 \dagger\right)$ were obtained for impact categories of ADE, ADF, GW, OD, A and E. The normalization factor for GW accounted for $15.21 \%$ to the $\mathrm{NF}_{\text {world }}$, while the normalization factor for $\mathrm{E}$ contributed to $1.06 \%$ of the world factor. Compared with the normalization factors for European $\left(\mathrm{EU}_{25+3}\right.$ in Table $\left.\mathrm{S} 2 \dagger\right)$, Chinese normalization factors had the same orders of magnitude. Because of lacking relevant data, impact categories of HT, FAET and PO were unable to be calculated. In order to simplify the following calculation, these three indicators were normalized with the factors of $\mathrm{EU}_{25+3}$.

Characterization results calculated by CML method were normalized with the $\mathrm{NF}_{\text {world }}$ and $\mathrm{Ch}_{\mathrm{NE}}$, respectively (Table S3 $\dagger$ ). Using BEES as weighting method, normalization results were aggregated and similar comparative assessments were generated for the overall results obtained from both $\mathrm{NF}_{\text {world }}$ (Fig. 1a) and $\mathrm{Ch}_{\mathrm{NE}}$ (Fig. 1b). Both the total impact results indicated that raw wastewater (scenario-4) had the lowest total environmental impact despite that the effect of eutrophication potential was higher than other scenarios. Although scenario-1 had the highest total impact results, the contribution of impact categories to the total impact results presented different change trends. With the increase of treatment levels from scenario- 4 to scenario-1, indicators of GW, FAET, ADF and HT became more dominated in the overall results (Fig. 1a), accounting for $43.27 \%, 17.11 \%, 12.22 \%$ and $6.88 \%$ in scenario-1, compared with $2.16 \%, 5.92 \%, 0.92 \%$ and $1.07 \%$ in scenario-4. However, FAET was the only dominant indicator increasing with the changes of the scenarios (Fig. 1b), from $28.41 \%$ (scenario-4) to 82.26\% (scenario-1).

Different comparative results occurred between CML method (Fig. 1b) and e-Balance method (Fig. 1c), with the same normalization factor $\left(\mathrm{Ch}_{\mathrm{NE}}\right)$ and weighting method (BEES). The results from e-Balance showed that scenario- 4 had the highest aggregated score, indicating the highest total environmental impact which was opposite to the indication from results of CML. The substantial difference probably resulted from setting COD as an independent category in e-Balance, which could explain why the result of scenario-4 from e-Balance was 1.1 times higher than that from CML. When analyzing the contribution of main substances to eutrophication potential or water pollution potential (shown in Fig. 2), the COD in an independent category plus COD in eutrophication accounted totally for $62.0 \%$ in the aggregated score of scenario-4 from e-Balance, while COD only contributed to $20.25 \%$ of aggregated score of scenario-4 from CML. As for scenario-1, Fig. 1c showed the lowest aggregated score, suggesting that tertiary treatment had the lowest total environmental implication. This was significantly different from the implication of Fig. 1b. The main reason for the difference was lack of FAET category in e-Balance calculation, which would underestimate the negative environmental impact caused by the upgrading of treatment levels.

With the same CML method and $\mathrm{Ch}_{\mathrm{NE}}$, different weighting methods were employed and investigated to examine how they would impact the final results of the $\mathrm{CML}$ and $\mathrm{Ch}_{\mathrm{NE}}$ (Table $\mathrm{S} 4 \dagger$ ). Similar comparative results using weighting methods of EPA
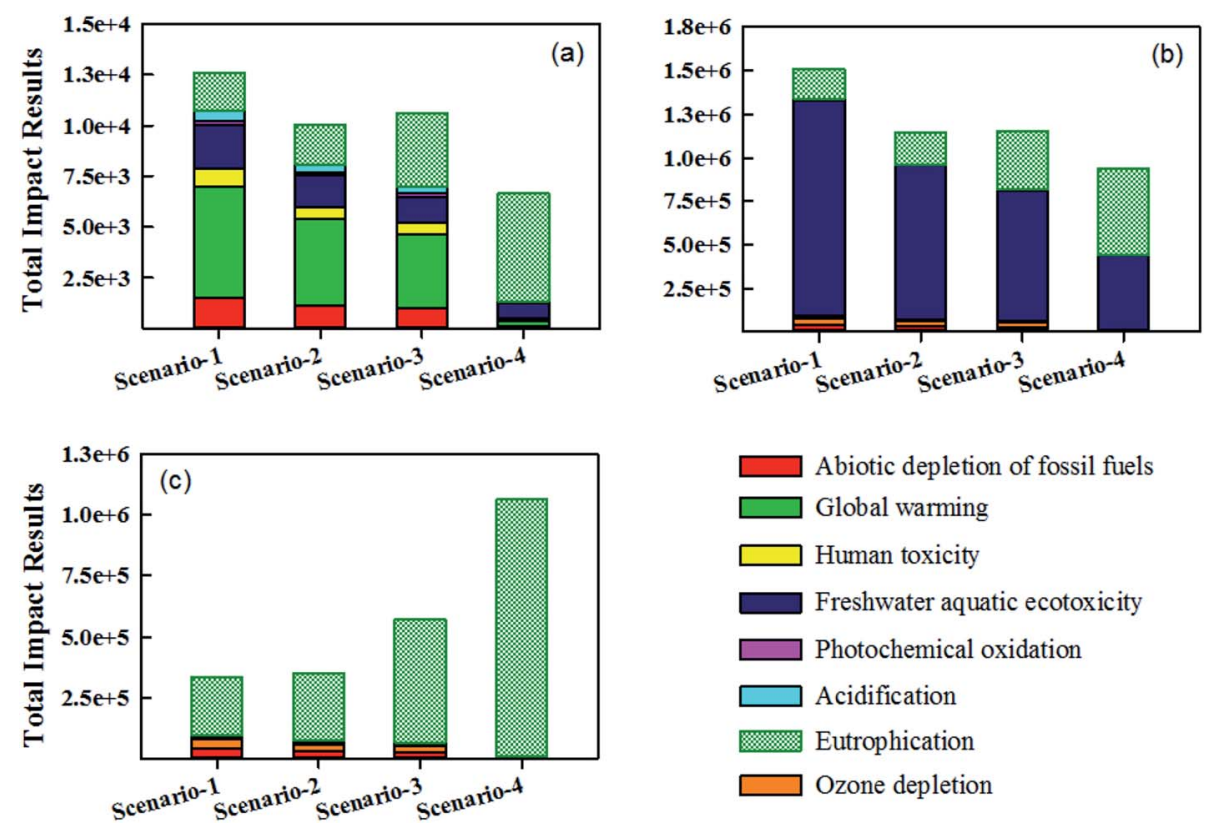

Fig. 1 Total impact of each scenario: (a) overall results obtained from NF World with CML method; (b) overall results obtained from Ch $\mathrm{NF}_{\mathrm{N}}$ with $\mathrm{CML}$ method; (c) overall results obtained from $\mathrm{Ch}_{\mathrm{NF}}$ with e-Balance method; *overall results were aggregated by BEES as weighting method, *results of eutrophication in (c) represented the aggregated scores of $E$ and COD. 


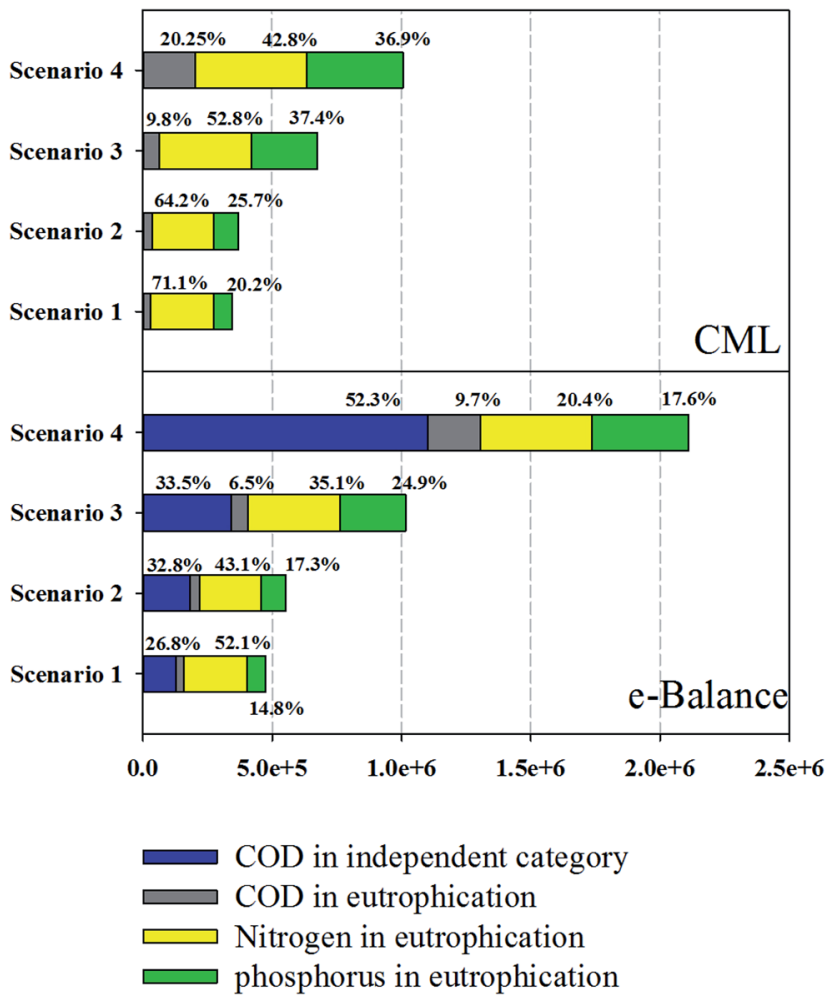

Fig. 2 Analysis of the contribution of the main substances involved in normalization results of eutrophication potential (CML) and water pollution potential (e-Balance).

and BEES were obtained (Fig. 3, EPA and BEES). That is, scenario-4 with the lowest ranking and scenario-1 with the highest ranking. During the increase of treatment levels, GW became the major contributor for both methods: $28.38 \%$ in scenario-1 and $27.88 \%$ in scenario-2 for the EPA method; $43.27 \%$ in scenario- 1 and $41.99 \%$ scenario-2 for the BEES method. Using the EDIP method, however, different overall results were obtained. Scenario-4 presented the highest result and scenario-2 had the lowest result (Fig. 3, EDIP).

By applying China-specific weighting methods, similar or comparable results with the EDIP method were harvested (Fig. 3, ECER-115, ECER-125 and ISCP-2009). COD was the main contributor to scenario-4 for both ECER-115 and ECER-125 methods, with the average percentage more than $96 \%$. Accompanying the increase of treatment levels to scenario-1, GW accounted for the overall impact was also increased to more than $40 \%$ when the ECER-115 method was applied, whereas ADF and GW accounted for more than 34\% using the ECER-125 as weighting method.

Synthesized factors were obtained from the following calculation to perform comparative estimates of total impact and eutrophication effect with the changes of scenarios under different weighting methods. With each weighting method, quantitative differences of weighting results among scenarios were calculated as follows:

$$
Q_{\text {Total }_{i, i-1}}=\sum_{j}\left(\mathrm{WR}_{i-1, j}-\mathrm{WR}_{i, j}\right)
$$

$$
\text { Eutro }_{i, i-1}=\mathrm{WR}_{i-1, \mathrm{E}}-\mathrm{WR}_{i, \mathrm{E}}
$$

where $i$ equals to 4, 3, 2 and represents specific scenarios; $j$ refers to the impact categories, which included ADF, GW, OD, HT, FAET, PO, A and E. $\mathrm{WR}_{i, j}$ is the weighting result of impact category $j$ for scenario $i$; $\left(\mathrm{WR}_{i-1, j}-\mathrm{WR}_{i, j}\right)$ is the quantitative difference of weighting results between scenario $i-1$ and scenario $i$ for impact category $j$; Eutro $_{i, i-1}$ means the difference in impact category E; $Q_{\text {Total }_{i,-1}}$ is the total differences in weighting results between scenarios, aggregating the value of $\left(\mathrm{WR}_{i-1, j}-\mathrm{WR}_{i, j}\right)$ for all impact categories.

Synthesized factors were calculated as follows:

$$
\begin{aligned}
\operatorname{SyT}_{i, i-1} & =\frac{Q_{\text {Total }_{i,-1}}}{\max |Q|} \\
\operatorname{SyE}_{i, i-1} & =\frac{Q_{\text {Eutro }_{i, i-1}}}{\max |Q|}
\end{aligned}
$$

where $\max |Q|$ means the maximum absolute value in $Q_{\operatorname{Total}_{i, i-1}}$; $\mathrm{SyT}_{i, i-1}$ is the total synthesized factor for changing scenario from $i$ to $i-1 ; \mathrm{SyE}_{i, i-1}$ is the eutrophication synthesized factor for changing scenario from $i$ to $i-1$. The synthesized factor ranged from -1 to 1 ; the value of 1 means the maximum environmental benefit, and the value of -1 means the maximum environmental burden. For the paradigm changing, synthesized factors greater than 0 means that there was benefit, and synthesized factors lower than 0 means that negative effect would occur.

The synthesized factors of eutrophication potential showed the similar results among all the weighting methods. The shift from scenario-4 to scenario-3 seemed to be the most desirable paradigm changing in terms of wastewater control only. For synthesized factors of total impact, the shift from scenario-4 to scenario-3 showed the maximum environmental burden in results of EPA (Fig. 4A) and BEES (Fig. 4B), but the maximum environmental benefit in all three China-specific weighting methods (Fig. 4D-F). All the weighting methods demonstrated that increasing levels from scenario-2 to scenario-1 would generate negative total environmental impacts, with synthesized factors ranging from -0.11 to -0.82 . With respect to the change from scenario-3 to scenario-2, the synthesized factors of EPA, BEES and EDIP exhibited the highest positive environmental implication, and all three China-specific methods also showed positive values around 0.13 to 0.15 .

\section{Discussion}

Comparative studies were performed in our present work to investigate whether the choice of China-specific normalization factors, LCIA methods, and weighting methods would generate results that were different from the site-generic LCA methods. In the case study, the application of Chinese normalization factors $\left(\mathrm{Ch}_{\mathrm{NE}}\right)$ had little influence on the comparison among scenarios in terms of total environmental impacts. However, large discrepancies were found in the contribution of toxicitybased indicator (FAET) when different normalization factors 

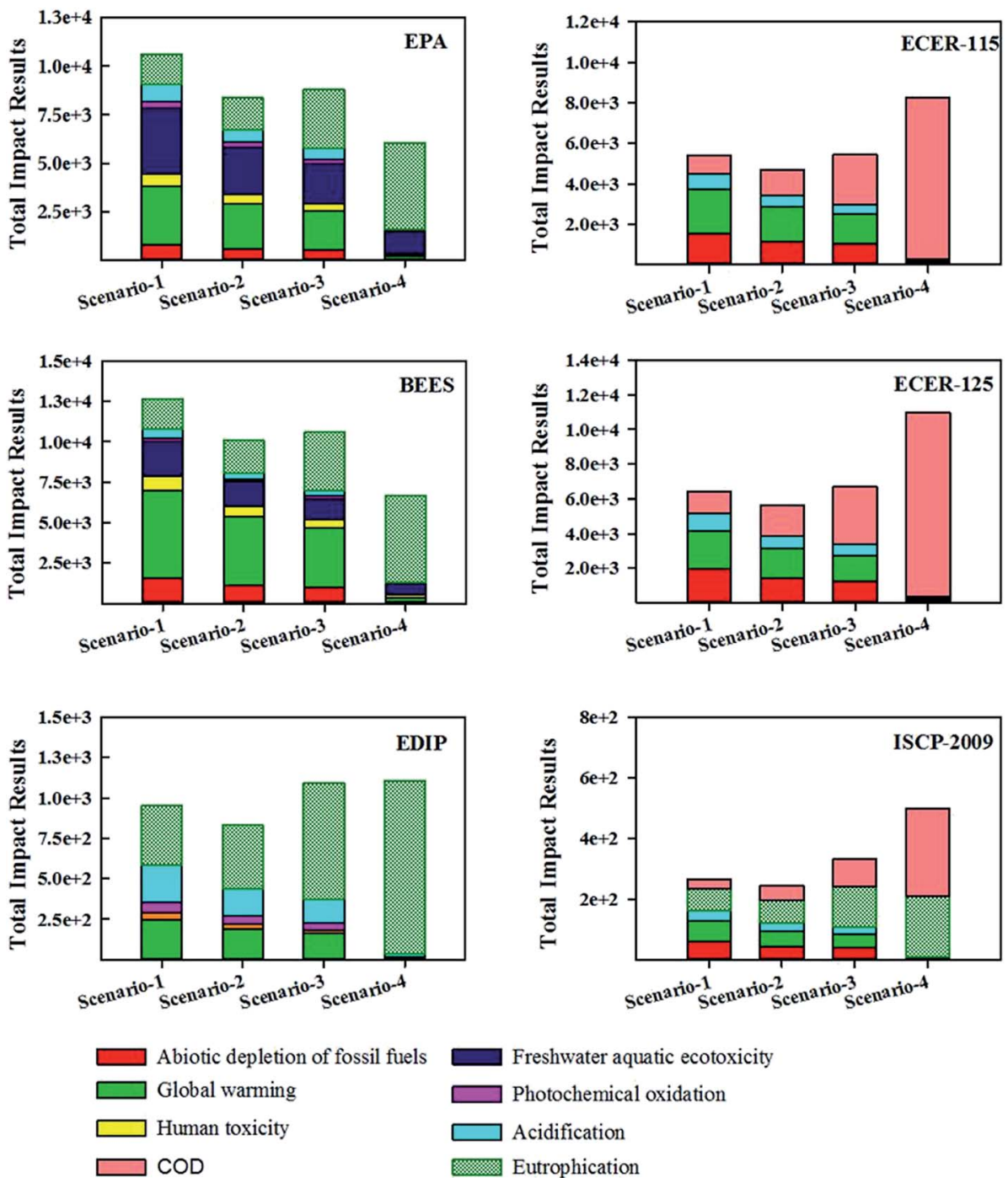

Freshwater aquatic ecotoxicity

Photochemical oxidation

Acidification

․․․․ Eutrophication

Fig. 3 Aggregated weighting results (representing total environmental impacts) from methods of EPA, BEES, EDIP, ecer-115, ECER-125 and ISCP-2009.

or different LCIA methods were used. FAET in results with $\mathrm{Ch}_{\mathrm{NE}}$ showed more contribution than that with $\mathrm{NF}_{\text {world }}$ (Fig. 1a and b), while results of e-Balance showed no impact of FAET (Fig. 1c). Methodologies differences (choice of normalization factors or LCIA methods) were the main reason causing the discrepancies, which are in consistent with previous literatures that results discrepancies existed generally because of e.g. the classification of toxicity-related impact categories or the choice of fate and exposure modelling. ${ }^{33,34}$ Notably, no toxicity-based impact category (e.g. FAET) was found in the China-specific LCA method, which means that future efforts could place emphasis on the development of toxicity-based indicators engaging specifically for China context.

Moreover, the choice of LCIA method and weighting methods did affect the final outcome. In particular with applying the LCA methods in combination with the weighting methods, the most substantial difference was the ranking of scenario-4: the lowest for site-generic methods, but the highest for the China-specific methods. With respect to the scenario-4 that represented the situation of discharging wastewater directly into local water bodies without any treatment, the lowest overall result meant that this situation had the most desirable total environmental implication and any levels of wastewater treatment would diminish the total environmental quality. This implication was largely against our common sense that the emission of raw wastewater would cause severe water pollution and ecological perturbation. If we assume the lowest overall result of scenario-4 as the abnormal LCA result, the application of China-specific LCIA methods or weighting methods in this sense would make the LCA results more reasonable and applicable.

COD being defined as an independent category was identified as the major cause that the result of scenario-4 for eBalance was higher than CML. Traditionally in LCA scientific background, COD was only considered as a contributor to eutrophication potential. Under the circumstance, nitrogen or 

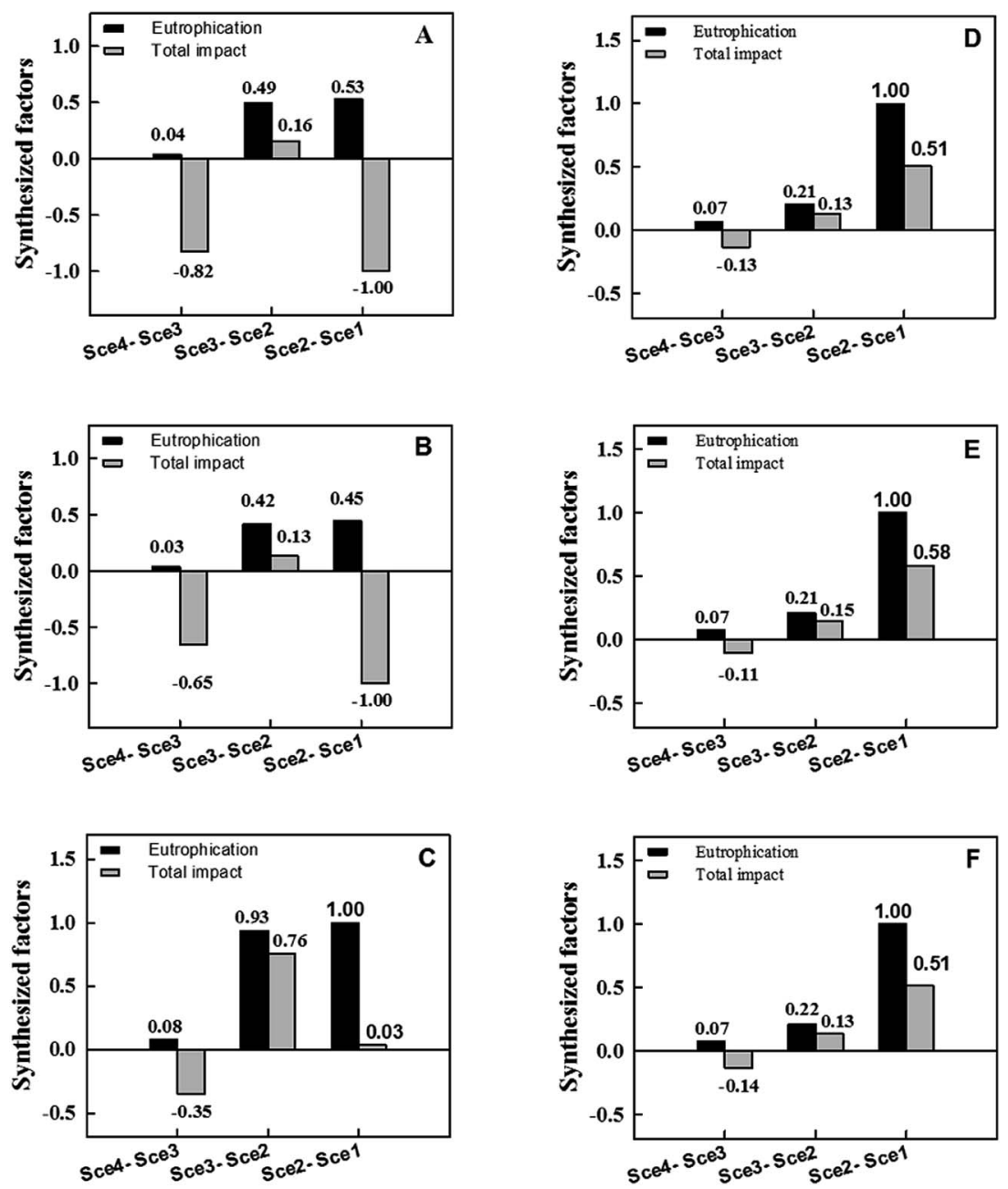

Fig. 4 Comparative estimates of total impact and eutrophication effect: (A) EPA; (B) BEES; (C) EDIP; (D) ECER-115; (E) ECER-125; (F) ISCP-2009.

phosphorus was often regarded as the limiting factor to the potential growth of alga, while the contribution of COD was insignificant. In fact, it was the potential depletion of oxygen that was measured to quantify eutrophication potential in LCA characterization models. However, besides eutrophication, another type of water pollution causing depletion of oxygen is the growth of bacteria in receiving waters. The released organic matter in wastewater can trigger the growth of bacteria, and the bacterial metabolic activity would consume large quantity of dissolved oxygen. Once the environmental capacity was not enough to contain the organic matter, it would results in severely contaminated state of the receiving waters. Integration of this type of water pollution to LCA assessing framework (i.e., setting COD as an independent category) is one possible approach. This addition of COD category needs to be determined according to the specific conditions of LCA case analysis. The design of e-Balance categories was on the basis of Chinese practice, and thereby seemingly the application of e-Balance obtained a more reasonable LCA overall result.

Regarding the weighting methods, although using Chinaspecific methods different results were obtained with sitegeneric methods (EPA and BEES), the results of EDIP were similar with those of ECER-115, ECER-125 and ISCP-2009. The similarity means where the weighting methods stood for was not the only factor affecting the final LCA results. The common features between EDIP and China-specific methods were that the impact category of FAET was not included into the weighting factors. The lack of FAET category would make the contribution of other impact categories relatively higher, for example the contribution of E to scenario-4 shown in Fig. 1c, and lead to the relatively less negative environmental impact caused by the increase of treatment levels. There was one similarity in the final results between China-specific methods and site-generic methods. Regarding the scenario shift from scenario-2 to scenario-1, all results showed negative synthesized factors, indicating that the upgradation from intermediate treatment to tertiary treatment would not be recommended by all the weighting results, no matter which weighting methods were used.

The application of China-specific LCIA method and weighting methods has been demonstrated to be able to obtain quite different LCA results associated with different implications, compared with site-generic LCA methods. The key feature relevant to wastewater treatment case was the direct impact of pollutants on local aquatic environment, which means that the 
site-generic results of generic LCA were likely not enough to obtain reasonable assessment results. The effect of aquatic pollutants on regional environment was influenced by many factors such as the emission point, the water temperature, the self-cleaning ability of receiving waters, et cetera. In future, more region-specific characterization models are needed to consider the migration and transformation of water pollutants and to characterize the accurate effect on local aquatic environment. Moreover, weighting factors for Chinese LCA application need to be further developed based on societal preferences as a whole and the national average indexes need to be considered in the design of weighting factors. Thereby, the LCA practitioner can apply them in a wide range of products and service.

\section{Acknowledgements}

This work was supported by the National Key R\&D Program (No. 2016YFC0401105).

\section{References}

1 S. Hellweg and L. Mila i Canals, Science, 2014, 344, 11091113.

2 J. B. Guinee, R. Heijungs, G. Huppes, A. Zamagni, P. Masoni, R. Buonamici, T. Ekvall and T. Rydberg, Environ. Sci. Technol., 2011, 45, 90-96.

3 H.-J. Klüppel, Int. J. Life Cycle Assess., 1998, 3, 301.

4 S.-O. Ryding, Int. J. Life Cycle Assess., 1999, 4, 307.

5 H. Lecouls, Int. J. Life Cycle Assess., 1999, 4, 245.

6 L. Corominas, J. Foley, J. S. Guest, A. Hospido, H. F. Larsen, S. Morera and A. Shaw, Water Res., 2013, 47, 5480-5492.

7 S. Lassaux, R. Renzoni and A. Germain, Int. J. Life Cycle Assess., 2007, 12, 118-126.

8 X. Gabarrell, M. Font, T. Vicent, G. Caminal, M. Sarra and P. Blanquez, Int. J. Life Cycle Assess., 2012, 17, 613-624.

9 C. Alfonsin, R. Lebrero, J. M. Estrada, R. Munoz, N. J. Kraakman, G. Feijoo and M. T. Moreira, J. Environ. Manage., 2015, 149, 77-84.

10 N. T. Hancock, N. D. Black and T. Y. Cath, Water Res., 2012, 46, 1145-1154.

11 M. Meneses, H. Concepción and E. A. D. Vrecko, J. Cleaner Prod., 2015, 107, 3e661.

12 R. Rodríguez, J. J. Espada, M. I. Pariente, et al., J. Cleaner Prod., 2016, 124, 21-29.
13 S. Renou, J. S. Thomas, E. Aoustin and M. N. Pons, J. Cleaner Prod., 2008, 16, 1098-1105.

14 M. Ortiz, R. G. Raluy and L. Serra, Desalination, 2007, 204, 121-131.

15 Y. Li, X. Luo, X. Huang, D. Wang and W. Zhang, J. Cleaner Prod., 2013, 57, 221-227.

16 S. Bai, X. Wang, G. Huppes, X. Zhao and N. Ren, J. Cleaner Prod., 2017, 144, 1-7.

17 J. C. Pasqualino, M. Meneses, M. Abella and F. Castells, Environ. Sci. Technol., 2009, 43, 3300-3307.

18 J. K. Choe, A. M. Bergquist, S. Jeong, J. S. Guest, C. J. Werth and T. J. Strathmann, Water Res., 2015, 80, 267-280.

19 X. H. Wang, X. Wang, G. Huppes, R. Heijungs and N. Q. Ren, J. Cleaner Prod., 2015, 94, 278-283.

20 J. B. Guinée, Int. J. Life Cycle Assess., 2001, 7, 311-313.

21 M. Hauschild and J. Potting, Environ. News, 2005, 80.

22 J. Bare, Clean Technol. Environ., 2011, 13, 687-696.

23 M. Goedkoop and R. Spriensma, Methodology Report, 2001.

24 O. Jolliet, M. Margni, R. Charles, S. Humbert, J. Payet, G. Rebitzer and R. Rosenbaum, Int. J. Life Cycle Assess., 2003, 8, 324-330.

25 M. Goedkoop, R. Heijungs, M. Huijbregts, A. De Schryver, J. Struijs and R. van Zelm, A life cycle impact assessment method which comprises harmonised category indicators at the midpoint and the endpoint level, 1, 2009.

26 L. B. Azevedo, A. D. Henderson, R. van Zelm, O. Jolliet and M. A. J. Huijbregts, Environ. Sci. Technol., 2013, 47, 1356513570.

27 A. M. Boulay, C. Bulle, J. B. Bayart, L. Deschenes and M. Margni, Environ. Sci. Technol., 2011, 45, 8948-8957.

28 A. W. Sleeswijk, Int. J. Life Cycle Assess., 2011, 16, 106-112.

29 A. Gallego, L. Rodriguez, A. Hospido, M. T. Moreira and G. Feijoo, Int. J. Life Cycle Assess., 2010, 15, 32-43.

30 R. J. K. Helmes, M. A. J. Huijbregts, A. D. Henderson and O. Jolliet, Int. J. Life Cycle Assess., 2012, 17, 646-654.

31 A. W. Sleeswijk, L. F. van Oers, J. B. Guinee, J. Struijs and M. A. Huijbregts, Sci. Total Environ., 2008, 390, 227-240.

32 S. Suh and B. C. Lippiatt, Int. J. Life Cycle Assess., 2012, 17, 604-612.

33 G. Geisler, S. Hellweg and K. Hungerbühler, Int. J. Life Cycle Assess., 2005, 10(3), 192.

34 R. Pant, G. Van Hoof, D. Schowanek, T. C. Feijtel, A. de Koning, M. Hauschild and R. Rosenbaum, Int. J. Life Cycle Assess., 2004, 9, 295-306. 